\title{
A novel technique to neutralize the Yawing moment due to asymmetric thrust in a hybrid buoyant aircraft
}

\author{
Anwar U Haque ${ }^{1}$, Waqar Asrar ${ }^{1, a}$, Ashraf A Omar ${ }^{2}$, Erwin Sulaeman ${ }^{1}$ and Mohamed J.S Ali ${ }^{1}$ \\ ${ }^{1}$ International Islamic University Malaysia (IIUM), 50728 Kuala Lumpur, Malaysia \\ ${ }^{2}$ University of Tripoli (UOT), P.O. Box 13154 Tripoli-Libya
}

\begin{abstract}
Dorsal fin is used in swimming animals like shark for the generation of thrust as well as to meet the requirement of the lateral stability. In the case of aircraft, rudders are normally used for the said requirement. In the present work, this nature inspired idea is explored for its application to neutralize the unavoidable asymmetric thrust produced by the twin engines of a hybrid buoyant aircraft. First, the estimation of asymmetric thrust is obtained with the help of analytical techniques for maximum thrust condition at 4 degree angle of attack. The moment generated by it is utilized for the sizing of a dorsal fin which looks similar to a tapered wing and is placed aft of the center of gravity. Wind tunnel testing at subsonic speed is carried out to explore the design features of this rotatable dorsal fin. It is found that a small rotation of 5 degree can generate the required moment. However, such rotation requires a complete pneumatic/electro-mechanical system and an alternative of it is to use a cambered airfoil for the dorsal fin installed at fixed location. Such a flow controlling device can also be used as an antenna mast, which is commonly installed out the fuselage of the aircraft for communication purposes. Moreover, by incorporating this technique, a pilot doesn't have to put an extra effort to make the aircraft stable in the presence of side wind.
\end{abstract}

\section{Introduction}

Studies related to static lateral stability of conventional and unconventional fuel powered twin engine aircraft, based on well-known design methods, are routinely done in industry, academia, and research labs and their results are mostly based on the analytical and experimental techniques. Such techniques can be employed to analyze the issues related to the asymmetric thrust of twin engines and its effect on the static lateral stability. Thrust produced by engine affects the overall static stability in three different ways [1]. First, the thrust produced by the propellers generated a moment about the center of gravity $C G$. Second, the influence of the propwash upon the aft portion of fuselage and on the tail surfaces. This effect is not so dominant if the engines are placed far away from the fuselage and the tail. The third one is a destabilizing moment due to the side force generated by the propellers [1], which is more critical for twin engine aircraft. The origin of this unbalanced torque in twin engine aircraft is not that both the engines turning in the same direction but it is due to the "P-Factor" [2]. The lift distribution over the propeller disk is always asymmetric, which tends to turn the aircraft to the right, if assuming an anticlockwise propeller [3]. This always requires rudder input for cancellation of the propellers' torque and for the said condition; the pilot has to turn the rudder to the left [4].
The turning angle of the rudder depends of the flying speed of aircraft and hence a function of the engine's power and $R P M$ of the propeller. Thrust loading of propeller produces a normal force when an aircraft is given an angle of attack.

Asymmetric thrust loading is always about the center of the thrust forces. It generates a small moment about the $C G$, if the engines are placed close of the fuselage. But the magnitude of the moment will be considerable for a short take-off and landing aircraft in which moment arm of thrust of engine is quite large due to voluminous space accommodated by the fuselage. Hybrid buoyant (HB) aircraft is one of the examples of such an aircraft in which partial takeoff weight is balanced by the aerostatic lift [5]. A complete detail about the anatomy of such an aircraft has been discussed in detail in section 3 . Although, such an aircraft is statically stable in longitudinal and lateral direction with power off [6]. But power on effects is yet to be explored, specially the influence of propulsion system in yaw stability. Asymmetric thrust is always a fatique for the pilot [4] as additional efforts has to be put by pressing the rudder pedal to counter balance the reading shown by the turn and bank indicator in the cockpit. Such a forced turning causes an increase in drag as well due to more frontal area of the aircraft exposed to the incoming air in flight.

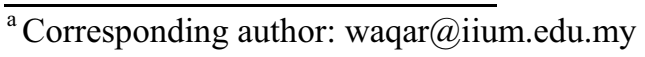


This requires special attention to explore a suitable option to minimize such affects.

Issue of asymmetric thrust is also quite critical in the climb and descent segment of takeoff and landing segment respectively, especially when the cross winds on the runway can trigger the asymmetric thrust loading. Also from the operational point of view, it requires additional assembly to deflect the rudder. For instance, in the case of the large aircraft, a pneumatically powered "rudder boost system" [7] is usually used, which require more operational and maintenance cost along with the weight penalty.

Flying altitude of a $H B$ aircraft is limited due to pressure height and in such an aircraft; the rate of climb is limited due to the constraint of ballonet's inflation [8]. Therefore, such aircraft does not leave a room for the pilot to neglect the said moment even during flight. It is infact of great importance to come up with some novel concept to counter measure the side force due to twin engines. In this regard, to the authors' best knowledge, no effort has been done in past for the control of such asymmetric side force by other alternative ways of active flow control. In the present research work, a novel concept is proposed to implant a small dorsal fin of the fuselage and behind the $C G$, which can generate an equivalent yaw force. This concept is perhaps derived from the nature by applying the potential advantages of dorsal fin in Shark fish, which lack swim bladders and any automatic neutral buoyancy [9]. This work is motivated due to huge amount of good work has gone on in past years on swimming animal, especially of sharks in which the dorsal fin/fins is movable [10-21]. Such motion becomes more interesting, when the tip of the fin is also deflectable to have additional component of lift in longitudinal direction. Such an aerodynamic component is hardly seen in bird in which both wings perform the same down stroke and up stroke simultaneously to generate the required thrust. Similar to a shark fish, a dorsal fin made up of a symmetric airfoil can be rotated in the lateral direction. But similar to a multi-element airfoil wing, it will require additional adds-on for the electro mechanical control. Also it will be a problem for breakage in communication, if such a fin is housing an antenna for communication, usually known as antenna mast [22].

Inplane forces due to the thrust produced by propeller engines can be derived by using Blade Element Theory, in particular for unconventional propeller shape. For conventional shapes, a $N A C A$ report contains theory for the estimation of propeller side force that can be used for either for angle of attack as well as yaw angle [23]. This work was placed into helpful curves by Seckel [24], which was further elaborated with the help of an example of fuel powered engine's propeller by [25]. These analytical relationships are used to get a first order approximation of yaw force, which is later utilized in designing a dorsal fin. Vertical tail itself has destabilizing effect on the longitudinal stability [1] and such an affect can be minimized by defining an anhederal angle to get a partial component of lift to balance such an affect. Anhederal angle is defined here as the tilt angle, once looking from the front view of the aircraft. Effect of anhederal and chamber of airfoil of such a dorsal fin is analyzed in the light of wind tunnel experiments for a dorsal fin made up of symmetric airfoil with a small anhederal angle. Although at certain angle of attack, the desired force requirement can be met but it requires a mechanical system to replace the muscles anatomy, which exist in swimming animals to turn the dorsal fin. However, a dorsal fin with a cambered one airfoil can do this job without additional weight penalty and it can meet the requirement of momentum to neutralize the counter moment of asymmetric thrust. This novel idea is discussed in this paper for its future application to keep the $H B$ aircraft to its original state, without any input by the pilot.

\section{Estimation of Asymmetric Thrust}

A three step methodology is adopted for the estimation of asymmetric thrust, Tab. 1. All the important input parameters required for three variables are highlighted in it.

Table 1. Methodology for the estimation of Asymmetric Thrust [25]

\begin{tabular}{|c|c|}
\hline \multicolumn{2}{|c|}{ Side Force Factor and Advance Ratio } \\
\hline $\begin{array}{c}\text { Area of Propeller's disk } \\
\text { Number of propellers }\end{array}$ \\
\hline \multicolumn{2}{|c|}{ Testing velocity } \\
RPM of propeller
\end{tabular}

Equation 1 represents an empirical method [25] for the estimation of the propeller normal force which is based upon propeller charts [23-24]. In this equation, $\mathrm{Ne}$ is the number of the blades per propeller, $A_{p}$ is the area of one propeller, $q$ is the dynamic pressure and $\alpha$ is the angle of attack. The function $f(T)$ adjusts for non-zero thrust and is given as function of coefficient of thrust, $C_{T}$ :

$$
T_{N}=q\left[N_{e} A_{p} \frac{d C_{N B}}{d \alpha} \frac{d \beta}{d \alpha} f(T)\right] . \alpha
$$

In order to evaluate the value of $T_{N}$ against $q$ equal to $750.3 \mathrm{~N} / \mathrm{m}^{2}$, value of $\frac{d C_{N B}}{d \alpha}$ and $\frac{d \beta}{d \alpha}$ were calculated first along with the value of $S F F$, which is equal to 14.82 against value of $A_{p}$. After doing an iterative calculation with a number of inputs, the equired value of against angle of attack equal to 4 degree comes out to be equal to $42.2 \mathrm{~N}$ and the moment generated by it is 304 N.m. Hence, based on the reference area of wing, the required coefficient of lift is equal to 0.0029 . 


\section{Details of the Configuration}

The configuration of HB aircraft consists of a voluminous fuselage to fulfill the requirement of volume for aerostatic lift and ballonets to control the expansion of the lifting gas. The fineness ratio of the aircraft is 5.5 which resembles that of a California Sea Lion; a hybrid buoyant aircraft by nature [26]. Two fuel powered engines are installed on the ultralight weight wings of span $20 \mathrm{~m}$, reference area of the wing equal to $27.5 \mathrm{~m}^{2}$ and $1.5 \mathrm{~m}$ is its mean geometric chord. The $C G$ of the aircraft is about $15.1 \mathrm{~m}$, which is far ahead of the wing. An $H$-tail is selected for such a configuration to meet the requirement of longitudinal and lateral stability [27]. A pictorial view of the configuration is shown in figure 1(a). This figure also shows the direction of the moments generated by the propellers of the engines as well that produced by the lift force of the dorsal fin. The distance between the aerodynamic center of the dorsal fin and CG i.e. $X_{T}$ is about $C G$. Geometry of the fin is shown in figure $1(\mathrm{~b})$.

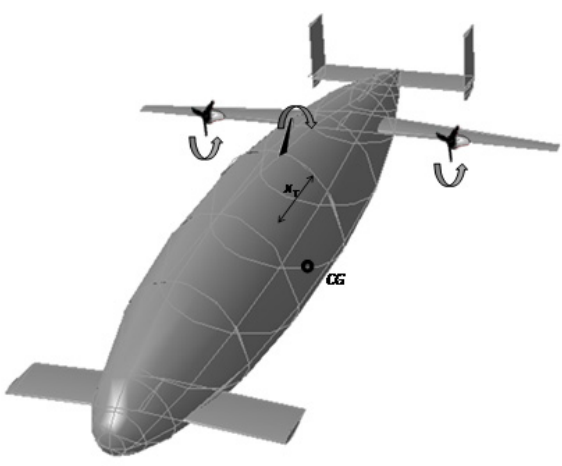

(a) HB aircraft

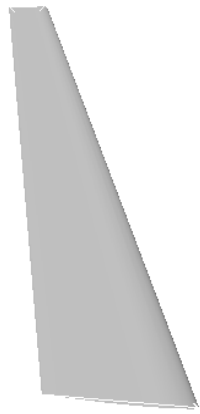

(b) Dorsal fin

Figure 1. Pictorial view of HB aircraft and dorsal fin

It is believed that the shape of dorsal fin in swimming animals is symmetrical and is perpendicular to the body. Such a shape is of interest for HB aircraft as well. This is due to interesting augmentation of the lift produced by its deflection in longitudinal as we all in in lateral direction. Aircraft always have some technological constrains due to a movable part. However, as mentioned earlier in the introduction part that a dorsal fin can be placed at constant incidence angle and the additional lift contribution in the longitudinal direction may be utilized for generating a negative pitching moment about the CG. However, the sizing of the dorsal fin depend on the required lift, which is calculated based on the asymmetric force generated by the propellers of the twin engines, discussed earlier in the section 2. The dorsal fin under study has span of $0.9 \mathrm{~m}$ and its mean aerodynamic chord is $0.28 \mathrm{~m}$. The root sand tip chord is equal to $0.40 \mathrm{~m}$ and $0.10 \mathrm{~m}$.

\section{Design of Experiment}

In the case of aircraft, the main contributor towards directional stability is vertical tail. When the airplane experiences side slip, the angle of attack of the vertical tail changes the lift so obtained is utilized to produce a yawing moment about center of gravity. The same concept is adopted here and a full model of dorsal fin, discussed in previous section is tested in IIUM wind tunnel. A rounded tip fairing was added to the wing tip and mounted vertically to the wind tunnel turn table, it has sweepback and sweep angles of leading and trailing edge are $30^{\circ}$ and $5^{\circ}$ respectively, with a tapered $N A C A$ 23012 profile and span of $0.9 \mathrm{~m}$. The wing taper ratio equal to $\lambda=0.25$ and aspect ratio of 7.2. The model is designed such that it has an inherent anhederal angel of 5 degree.

Model forces are measured with an external sixcomponent balance and the variation of the lift coefficient with angle of attack is shown in figure 2. The maximum lift coefficient is found to be equal to 0.887 . Due to reasonably small blockage ratio of $0.012(1.2 \%)$ at 4 degree angle of attack, no blockage correction was applied.

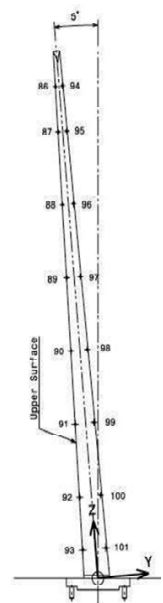

Figure 2. A Frontal view of the wing

\section{Results and Discussion}

The required value of $C_{L}$ is basically function of the reference area of the wing and the local value $C_{L}$ of the dorsal fin is based on its own reference area. Its estimated 
value is derived by plotting as function of angle of attack, Fig. 3. Against $\alpha$ equal to 8.5 degree, experimental value of $C_{L}$ is equal to about 0.45 , which is further nondimensionalized by the reference area of the wing to get the required $C_{L}$ equal to 0.0029 . This value is found to be consistent with that obtained by using panel method software. The distance between the aerodynamic center of the dorsal fin is taken at its quarter chord from the leading edge. In this way, the moment arm of the force generated by the dorsal fin is calculated to be equal to 6.2 m. Plot of $C_{L}$ as function of $\alpha$ is shown in figure 3. The plots of coefficient of pressure of this dorsal fin at $\alpha$ equal to zero degree and 8.5 degree are shown in figure 4(a) and 4(b), respectively.

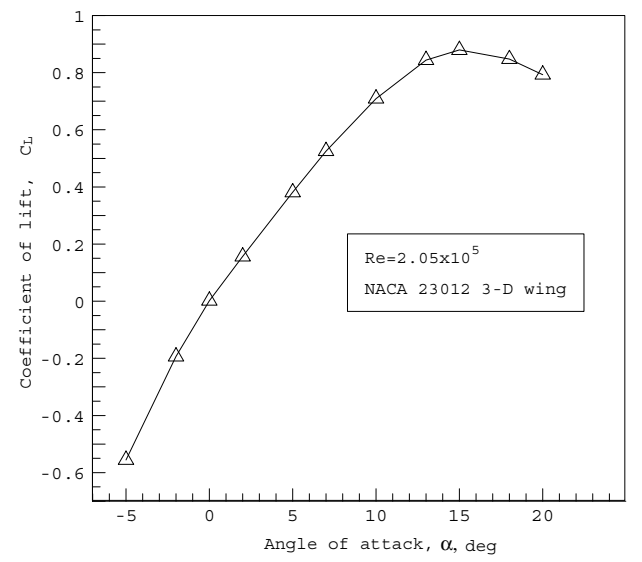

Figure 3. Plot of $C_{L}$ as function of $\alpha$
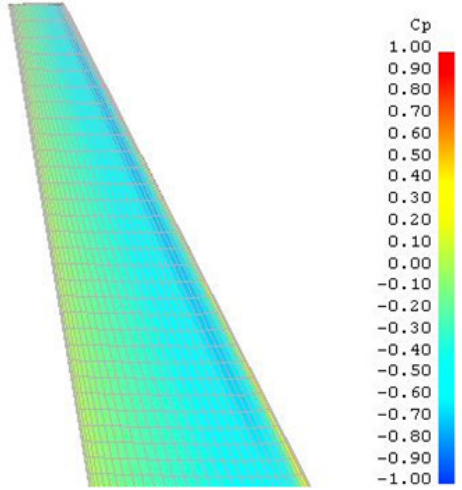

(a) Zero degree

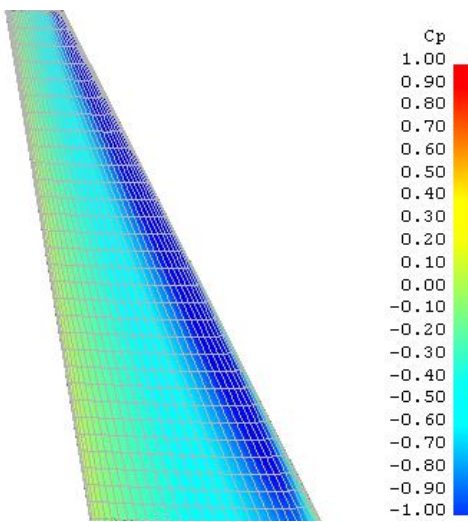

(b) 8.5 degree

Figure 4. Distribution of coefficient of pressure over cambered dorsal fin
For the option two case, NACA 4412 airfoil is selected after an iterative calculation to meet the requirement of the $C_{L}$ for zero degree angle of attack, for the same dimensions of the dorsal fin. It is important to note that the dorsal fins can be of a shape similar to that of marine animals as well. In this regard, pictorial view of two such fins is shown in figure 5 for quick reference. Such fins will have less span and bigger root chord. Only design requirement for it is to meet the said requirement of asymmetric thrust.

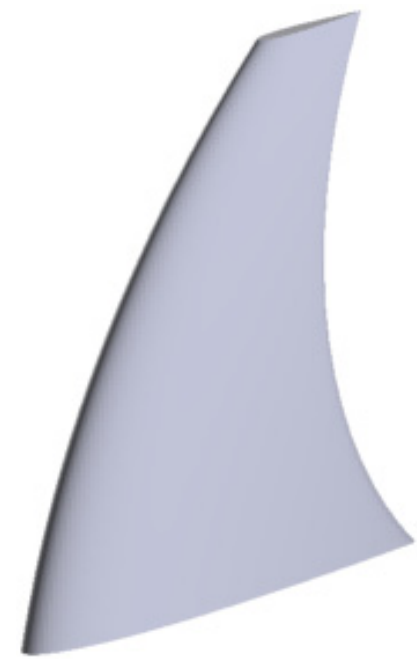

(a)

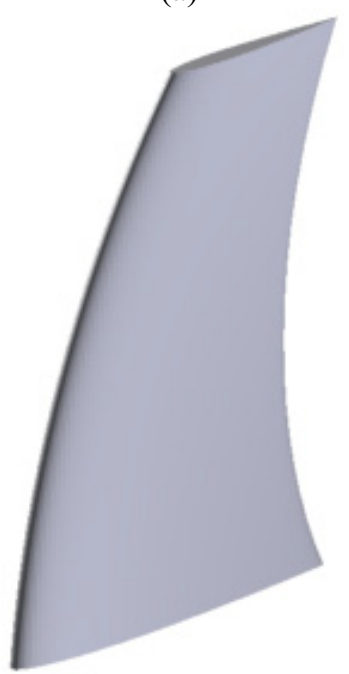

(b)

Figure 5. Alternative profiles of dorsal fins

The results so obtained will be applied in the conceptual design of such aircraft [26-27] and later, wind tunnel testing on its scaled down model for power-on condition. Furthermore, as the scope of this research is only limited to the yaw force generated by the propellers. Therefore, no calculations have been done to estimate the component of lift force generated by the dorsal fin, which contributes towards longitudinal stability.

The proposed concept does identify clearly any implications for research work for other applications. For example it can be applied to buoyant aerial vehicle, which utilizes DC electric brushless motors which has 
additional weight penalty due to massive battery to give power for the operation of motors. It can also be applied to under water hull as well for which a pin obstacle was recently proposed to act as a source of asymmetric normal force to improve the longitudinal stability. This phenomenon is similar to the asymmetric vertical flow which exists in aircraft which fly at high angle of attack.

Although no results were provided in this work to justify that the asymmetric normal force of the cambered shaped dorsal fin can be used in the longitudinal control of the HB aircraft, through induced pitching moment. But it is believed that an engineering method can be developed to validate the said concept. Furthermore, it is perceived that when the certification of such an aircraft will be done in future than such nature inspired concept will ease of the pilot in flight operation.

\section{Conclusion}

The proposed concept of dorsal fin is quite different than that traditionally used in aircraft with vertical tail to enhance the performance of vertical tail by generating the vortex flow ahead of it. As per the results of the generic model, it can be concluded that the proposed dorsal fin can intrinsically balance the asymmetric thrust for the condition that there is no offset of the thrust vector. Moreover, it will give a road map for future wind tunnel testing with bilateral propulsion system on such aircraft in which long moment arm for the dorsal fin is available.

\section{Acknowledgment}

The support of the Ministry of Science, Technology and Innovation (MOSTI), Malaysia, under the grant 06-0108-SF0189 is gratefully acknowledged. Authors are thankful to Senior Engineer Azliza Binti Embong, Nor Hafiz Adnan and Firdauz Hakem for providing assistance during the experimental work.

\section{References}

1. Raymer, D., Aircraft Design: A Conceptual Approach, Washington, DC: American Institute of Aeronautics and Astronautics, Inc., (2012)

2. Cover, A.B, Engine Response to Distorted Inflow Conditions, AGARD Report, (1986)

3. Shin, H. J., Lee, J. S., Lee, K. H., Han, M. R., Hur, E. B., \& Shin, S. C. Numerical and experimental investigation of conventional and un-conventional pre swirl duct for VLCC. International Journal of Naval Architecture and Ocean Engineering, 5 3, 414-430 (2013)

4. McRuer, D. T., Graham, D., and Ashkenas, I. Aircraft dynamics and automatic control. Princeton University Press. (2014)

5. Haque, A. U., Asrar, W., Omar, A. A., Sulaeman, E., and Ali, J. S. M., Effect of Wing Loading on Gross Takeoff Mass of a Hybrid Buoyant Aircraft, International Aerospace Engineering Conference, 2728 August, 2015 - Vancouver, Canada (2015).
6. Haque, A. U., Asrar, W., Omar, A. A., Sulaeman, E., and Ali, J. S. M., Power-off static stability analysis of a clean configuration of a hybrid buoyant aircraft, $7^{\text {th }}$ Ankara International Aerospace Conference, METU, Ankara Turkey, 11-13 September (2015)

7. Wallace, F. R., \& Hein, J. N. U.S. Patent No. 5,238,207. Washington, DC: U.S. Patent and Trademark Office, (1993)

8. Haque, A. U., Asrar, W., Omar, A. A., Sulaeman, E., and Ali, J. S. M., Assessment of Engine's Power Budget for Hydrogen Powered Hybrid Buoyant Aircraft, Journal of Propulsion and Power Research, Elesvier (in press), (2015)

9. Nakamura, I., Meyer, C. G., \& Sato, K. (2015). Unexpected Positive Buoyancy in Deep Sea Sharks, Hexanchus griseus, and a Echinorhinus cookei. PloS one, 10(6).

10. J. E. Harris, The role of the fins in the equilibrium of the swimming fish. I. Wind-tunnel tests on a model of Mustelus canis (Mitchill). Journal of Experimental Biology 13, 476-493, (1936)

11. J. E. Harris, The mechanical significance of the position and movements of the paired fins in the Teleostei.Papers from Tortugas Laboratory 31, 173189, (1973)

12. J. E. Harris, 1938. The role of the fins in the equilibrium of the swimming fish. II. The role of the pelvic fins. Journal of Experimental Biology 15, 3247, (1938)

13. J. E. Harris, (1953). Fin patterns and mode of life in fishes. In S. M. Marshall and P. Orr (eds), Essays in Marine Biology, Oliver \& Boyd, Edinburgh, (1953)

14. P.W. Webb, (1975). Hydrodynamics and energetics of fish propulsion. Bulletin of the Fisheries Research Board of Canada 190 1-158, (1975)

15. P. W. Webb, Simple physical principles and vertebrate aquatic locomotion. American Zoologist 28 709-725, (1988).

16. P. W. Webb, Designs for stability and maneuverability in aquatic vertebrates: What can we learn. In: Tenth International. Symp. Unmanned Untethered Submersible Tech.: Proc. Sp. Ses. BioEng Res. Related to Autonomous Underwater Vehicles, Durham, NH, 85-108, (1997).

17. P. W. Webb, Control of posture, depth, and swimming trajectories of fishes. Integrative and Comparative Biology 42 94-101, (2002).

18. P.W. Webb, and Keyes, R, Swimming kinematics of sharks. Fish. Bull. 80 803-812, (1982)

19. D. Weihs, (1989). Design features and mechanics of axial locomotion in fish. American Zoologist 29:151160.

20. D. Weihs, Stability of aquatic animal locomotion. Cont. Math. 141 443-461, (1993)

21. D. Weihs, (2002). Stability versus maneuverability in aquatic locomotion. Integrative and Comparative Biology Experimental Biology, 42 127-134, (2002)

22. Burnside, W. D., \& Marhefka, R. J. Antennas on aircraft, ships, or any large, complex environment. An Antenna handbook, Springer US, 1435-1534, (1988) 
23. Rebneb, B. H. S., Formulas for propellers in yaw and charts of the sede-force derivative, (1943)

24. Seckel, E., \& Morris, J. J., The Stability Derivatives of the Navion Aircraft Estimated by Various Methods and Derived from Flight Test Data (No. AMS-923). Princeton University, Dept. of Aerospace and mechanical sciences, (1971)

25. Gudmundsson, S., General aviation aircraft design: Applied Methods and Procedures. ButterworthHeinemann, (2013)

26. Haque, A. U., Asrar, W., Omar, A. A., Sulaeman, E., and Ali, J. S. M., A Novel Design of a Hybrid Buoyant Aircraft- A Potential Greener Solution for Inter Connectivity of Malaysian Islands", AER0 15, 19-21 April, 2015, Monterial Canada, (2015)

27. Haque, A. U., Asrar, W., Omar, A. A., Sulaeman, E., and Ali, J. S. M., (2015) "Pugh Analysis for Configuration Selection of a Hybrid Buoyant Aircraft", SAE 2015 AeroTech Congress \& Exhibition, September 22-24, Seattle, Washington, USA, (2015) 